\title{
Laryngeal sequelae following prolonged intubation: A prospective study
}

\author{
V. Rangachari, I. Sundararajan, V. Sumathi, K. Krishna Kumar
}

Background: Laryngeal injuries following intubation have a reported incidence from 63 to $94 \%$ and
permanent sequelae are reported to be about 10 to $22 \%$ in the world literature. While several studies
assessing the laryngeal complications are available in Caucasoid populations, minimal data is available in
the literature regarding south Indian population. Aim: The aim of this study was to evaluate laryngeal
lesions in patients after prolonged intubation ( $>24 \mathrm{~h})$, to correlate these lesions with the variables involved
in the process of intubation and to determine the risk factors. Materials and Methods: This is a prospective
study for 1 year of patients who were intubated for more than $24 \mathrm{~h}$ in our critical care unit. Patients underwent
laryngeal video endoscopy on the day of extubation and after 3 weeks by an ENT surgeon who was blinded
to the intubation variables. Result: About 51 patients were included in the study. Laryngeal abnormalities
were seen in 41 patients on the day of extubation. At the end of third week after extubation, only 10 patients
had abnormal laryngeal findings. A multivariate stepwise regression model showed that bigger tube size
$(P=0.02)$, longer duration of intubation $(P=0.01)$ and emergency intubation $(P=0.02)$ was associated with
higher incidence of laryngeal complications on the day of extubation. At the end of third week laryngeal
findings were influenced only by the duration of intubation $(P=0.001)$. Conclusion: Laryngeal sequelae
after extubation is directly associated with duration of intubation.
Key words: Endotracheal intubation, laryngeal injury, laryngeal video endoscopy

At present critical care units have a significant number of patients who require intubation for prolonged periods of time. While the indications for intubation are varied, it is commonly used for ventilatory assistance, relief of upper airway obstruction and to aid in tracheobronchial toileting. With the advent of high volume low-pressure tubes, it is common for the patients to be ventilated through the endotracheal tube for up to 3 weeks. The sequelae of intubation depend on multiple factors and

\section{From:}

Department of Otorhinolaryngology, Sundaram Medical Foundation, Anna Nagar, Chennai - 600040 , India

\section{Correspondence:}

Dr. Indu Sundararajan, Department of Otorhinolaryngology, Sundaram Medical Foundation, IV Avenue, Shanthi Colony, Anna Nagar, Chennai - 600 040, India. E-mail: indusrihari1@yahoo.com can also at times be a major source of morbidity to the patient during recovery. Laryngeal complications after prolonged intubations have varied incidence rates in the literature. Hoarseness of voice, cough, dysphagia, aspiration and stridor can develop after extubation. Laryngeal evaluation of such patients becomes necessary to assess the nature of airway injury. Common injuries following long-term intubation can manifest in the form of erythema, ulceration, granulomas [Figure 1], arytenoid dislocations, ${ }^{[1-3]}$ subglottic stenoses and vocal fold immobility. ${ }^{[4-8]}$

Racial and ethnic features may determine the dimensions of the pharynx and larynx and may play a role in the development of intubation related 
complications. Our group has previously described a very high incidence of postintubation stridor in women in south Indian ICU. ${ }^{[9]}$ While several studies assessing the laryngeal complications are available in Caucasoid populations minimal data is available in the literature regarding south Indian population. Therefore we prospectively evaluated the laryngeal lesions in patients after prolonged intubation to determine the association with risk factors. The ethics committee of the hospital approved the study and informed consent was obtained from all subjects.

\section{Materials and Methods}

This prospective study was conducted in Sundaram Medical Foundation, Chennai, a 140-bedded hospital with a 16-bedded Intensive Care unit for 1 year from September 2002 to August 2003. All patients, age $>14$ years, extubated at the intensive care unit of our hospital after at least $24 \mathrm{~h}$ of intubation were included in the study. Laryngeal examination was done on the day of extubation and 3 weeks later with a rigid 70 , direct laryngeal videoendoscopy by the ENT surgeon who was blinded to the intubation variables. Patients who subsequently underwent tracheostomy, history of previous intubation within 8 weeks, intubations done outside this hospital and accidental extubation were excluded from the study.

The association of laryngeal findings with demographic details along with medical history (cigarette smoking, COPD, diabetes mellitus and congestive heart failure) and intubation variables [nature of intubation (emergency or elective), size of endotracheal tube, skill of intubating personnel (Consultant/ Resident), cuff pressure during the intubated period, total period of intubation] were studied.

\section{Statistical analysis}

The results were analyzed using STATA 7.0 statistical software. Parametric (normally distributed) data were analyzed using $t$-test for group comparisons. Nonparametric (skewed) data were analyzed using Kruskal-Wallis test. Univariate correlation between presence of laryngeal complications and parametric variables was done using Spearman's coefficient of correlation. Chi-square test was used to analyze data computed with a $2 \times 2$ table. A stepwise multivariate regression model was used to correlate the variables found significant in univariate analysis.

\section{Results}

About 51 patients were included in the study. The demographic data as shown in Table 1 did not influence the laryngeal findings on the day of extubation and after 3 weeks.

Laryngeal abnormalities were seen in 41 of the 51 patients during examination on the day of extubation. The most common feature was vocal cord erythema, which was present in nearly half the patients. [Figure 1] shows the various complications seen and their frequencies on the day of extubation. At the end of 3 weeks after extubation, only 10 patients had abnormal laryngeal findings [Figure 2]. Vocal cord granuloma was the most common feature in the set of abnormal findings at 3 weeks.

Table 2 shows data regarding intubation variables and their association with the laryngeal sequelae on the day of extubation and after 3 weeks. Univariate analysis of the intubation variables showed larger endotracheal tube size $(P=0.04)$, skill of intubating doctor (consultant or registrar; $P=0.02$ ), nature of intubation (elective or emergency; $P=0.07$ ) and longer duration of intubation $(P=0.01)$ influenced postextubation laryngeal sequelae. When subjected to statistical multivariate analysis, larger endotracheal tube size $(P=0.04)$, emergency intubation $(P=0.02)$ and prolonged intubation $(P=0.005)$ were the only significant factors associated with the laryngeal findings on the day of extubation as shown in Table 3. The presence of laryngeal complications at the end of 3 weeks after extubation was related only to the duration of intubation $(P=0.001)$.

\section{Discussion}

Patients needing ventilation through artificial airways in the ICU is a common occurrence. Laryngeal injuries

\begin{tabular}{|c|c|c|}
\hline Patient attributes & Number & $P$ value-3 weeks \\
\hline Age & $\begin{array}{l}\text { Mean: } 50.23 \\
\text { Range: } 17-85\end{array}$ & 0.27 \\
\hline BMI & $\begin{array}{c}\text { Mean: } 24.66 \\
\text { Range: } 8.11-40.05\end{array}$ & 0.74 \\
\hline Gender & $\begin{array}{c}\text { Male: } 41 \\
\text { Female: } 10\end{array}$ & 0.27 \\
\hline Smokers & $\begin{array}{c}\text { Smokers: } 12 \\
\text { Nonsmokers: } 39\end{array}$ & 0.11 \\
\hline Diabetes mellitus & 10 & 0.32 \\
\hline Congestive heart failure & 7 & 0.09 \\
\hline COPD & 7 & 0.37 \\
\hline
\end{tabular}

COPD - Chronic obstructive pulmonary diseases 


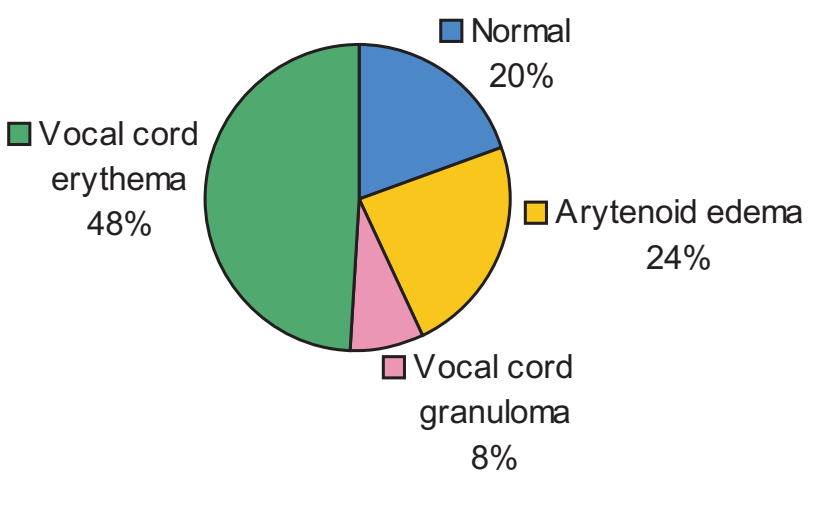

Figure 1: Laryngeal sequelae at initial examination

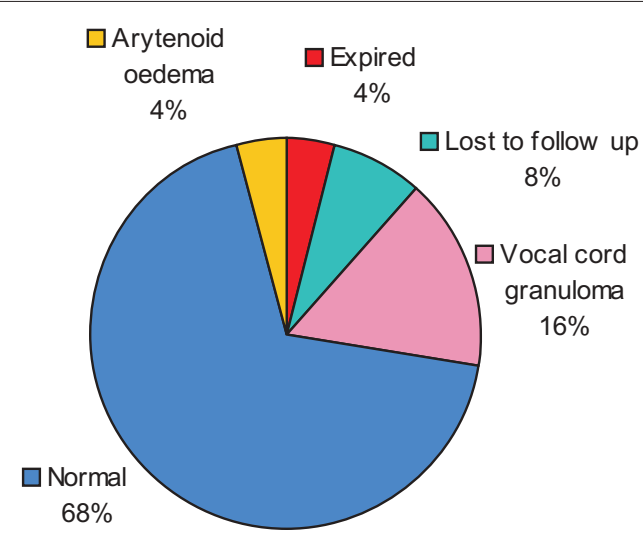

Figure 2: Follow up at the end of three weeks

\begin{tabular}{|c|c|c|c|c|}
\hline Intubation variables & & Total & $\begin{array}{l}\text { Laryngeal complications on } \\
\text { the day of extubation }\end{array}$ & $\begin{array}{c}\text { Laryngeal complications } \\
\text { after } 3 \text { weeks }\end{array}$ \\
\hline \multirow[t]{2}{*}{ Nature of intubation } & Elective & 28 & 20 & 4 \\
\hline & Emergency & 23 & 21 & 6 \\
\hline \multirow[t]{2}{*}{ Intubating doctor } & Consultant & 36 & 26 & 4 \\
\hline & Resident & 15 & 15 & 6 \\
\hline \multirow[t]{4}{*}{ Tube size (mm) } & 7 & 2 & 1 & 0 \\
\hline & 7.5 & 15 & 10 & 1 \\
\hline & 8 & 32 & 28 & 8 \\
\hline & 8.5 & 2 & 2 & 1 \\
\hline \multirow[t]{4}{*}{ Duration of intubation (Days) } & $<1$ & 11 & 2 & 0 \\
\hline & $2-4$ & 19 & 18 & 1 \\
\hline & $5-7$ & 15 & 15 & 3 \\
\hline & $>7$ & 6 & 6 & 6 \\
\hline
\end{tabular}

Table 3: Statistics intubation attributes (multivariate analysis)

\begin{tabular}{lcc}
\hline Variable & $\boldsymbol{P}$ value-day 1 & $\boldsymbol{P}$ value-day 21 \\
Intubating doctor & 0.113 & 0.279 \\
Nature of intubation & 0.0023 & 0.041 \\
Tube size & 0.040 & 0.176 \\
Duration of intubation & 0.005 & 0.001 \\
\hline
\end{tabular}

following intubation have a reported incidence from $63^{[10]}$ to $94 \%{ }^{[5]}$ and permanent sequelae are reported to be about $10^{[10]}$ to $22 \%{ }^{[8]}$ in the world literature. Earlier, tracheostomy was done when the decision for prolonged intubation was made to avoid the laryngeal injuries. Improvement in cuff design (high volume low pressure cuffs) has permitted prolonged ventilation through endotracheal tube. The time to switch over from endotracheal tubes to tracheostomy is controversial. Current data suggest that ventilation through high volume low-pressure endotracheal tubes are the method of choice of artificial airway up to 3 weeks. ${ }^{[11]}$ The laryngeal injuries can vary from mucosal injuries like vocal cord erythema, edema, granulations and ulcerations to more permanent sequelae like arytenoids dislocation, ${ }^{[1-3]}$ vocal cord palsy ${ }^{[4-6]}$ and subglottic stenosis. ${ }^{[4,10]}$ In our study vocal cords and the arytenoids were the only components of the larynx involved in injuries. There were no patients with vocal cord paralysis, arytenoid dislocations or tracheal and subglottic stenosis in this study population.

Risk factors like smoking, ${ }^{[12]}$ diabetes mellitus, ${ }^{[13]}$ COPD, congestive heart failure ${ }^{[13]}$ were not associated with the laryngeal sequelae as reported in the literature. The study population had a $42 \%$ incidence of patients with comorbidities. Though the co-morbidities would have probably influenced the duration of intubation indirectly, they did not seem to have any direct influence on the presence of laryngeal complications. Chronic obstructive pulmonary disease and smoking, though expected to contribute to the presence of laryngeal injuries, did not do so in our study. It is likely due to the small number of patients with these conditions.

Age, gender, height, weight and Body Mass Index did not affect the occurrence of laryngeal sequelae. The female gender is expected to be more prone to laryngeal injuries due to the smaller size of their larynges. An earlier 
retrospective study ${ }^{[9]}$ of 304 patients in our intensive care unit by Rajagopalan et al. ${ }^{[9]}$ had shown female gender was shown to be a significant predictor of post-extubation stridor $(P=0.0003)$. In our study, laryngeal sequelae were not associated with gender.

Laryngeal injuries are seen in patients intubated with larger size endotracheal tube. The determination of tube size of an adult patient is usually based on the physician's assessment of neck morphology and external features of the larynx. There is no standard formula to serve as a guide to appropriate tube size. A size eight endotracheal tube is generally used for adults and size 7 or 7.5 for small built adults.

Literature ${ }^{[10,14]}$ shows increased incidence of laryngeal injuries with higher cuff pressures. In our study population, $90 \%$ of the patients had a standard cuff pressure of $30 \mathrm{~cm} \mathrm{H}_{2} \mathrm{O}$. The cuff pressure is maintained as per the recommended guidelines and is monitored twice a day in our intensive care unit. The cuff restricts the flow of blood through the tracheal tissues thus causing ischaemic damage. The use of high-volume, lowpressure endotracheal tubes is also a routine practice in our intensive care unit. These tubes have a cuff with a large resting volume and diameter and a thin compliant wall that allows a seal with the trachea to be achieved without stretching its wall. This reduces the risk of injury to tracheal tissues, there by reducing the risk of significant cuff-induced complications following prolonged intubation.

The association of more laryngeal complications with emergency intubations is an expected occurrence. Intubations done in the emergency sitting have the disadvantages of less preparation, inadequate patient sedation and less co-operation on the part of the patient that can be responsible for higher occurrence of laryngeal injuries.

The skill of the intubating physician also plays an important role in the genesis of laryngeal injuries. The residents and trainees with less skill and experience have comparatively greater association with complications than the consultants. However, the fact that the skill of the intubating physician becomes insignificant on multivariate analysis gives an impression that the other factors in selection of tube size, the duration of intubation and the circumstances of intubation have a greater relevance and significance. Use of appropriate tube size and monitoring of duration of intubation is essential in the prevention of laryngeal injuries.

\section{Summary and Conclusion}

Prolonged laryngeal complications are rare but important sequelae of artificial airways. Initial laryngeal injuries are quite common (80\%). Most of the patients tend to recover, as these are superficial mucosal injuries. Only about $20 \%$ of the patients had permanent sequelae. In this study, a stepwise multivariate regression model showed that post-extubation laryngeal injuries on the day of extubation were associated with larger tube size, emergency intubation and longer duration of intubation. At the end of three weeks, duration of intubation was the only predictor of post extubation laryngeal sequelae.

Use of high-volume, low-pressure cuffs and regular monitoring of cuff pressures seems to decrease the laryngeal injuries secondary to prolonged intubation. Use of appropriate tube size and monitoring of duration of intubation is of paramount importance. A systematic laryngeal examination after extubation, whenever indicated, decreases the secondary sequelae by initiating appropriate measures when necessary.

The small number of patients as well as the decision to exclude patients, who underwent tracheostomy, limits our study. It is possible that many patients underwent tracheostomy due to laryngeal lesions and were not represented in the study.

Large multi-centre studies with bigger cohorts are needed to definitely establish the role of medical disorders and other parameters in producing laryngeal complications in patients with prolonged intubation.

\section{Acknowledgements}

Authors acknowledge Dr Arjun Rajagopalan, Medical Director, Sundaram Medical Foundation, Chennai for permitting the study to be conducted in the hospital and for his suggestions, Dr. Ram E. Rajagopalan, Dr. S. Mahendran and Dr. R. Rajaram Consultants in Department of Critical Care, for permitting the study to be conducted in the ICU and also helping in the study design, Dr. Srihari Veeraraghavan Consultant Pulmonologist and Intensivist for helping in the statistical analysis and presentation and Dr. P Nataraj ENT Consultant. 


\section{References}

1. Rudert H. Uncommon injuries of the larynx following intubation. Recurrent paralysis, torsion and luxation of the cricoarytenoid joints. HNO 1984;32:393-8.

2. Rieger A, Hass I, Gross M, Gramm HJ, Eyrich K. Intubation trauma of the larynx: A literature review with special reference to arytenoid cartilage dislocations. Anasthesiol Intensivmed Notfallmed Schmerzther 1996;31:281-7.

3. Obrebowski A, Wojnowski W. Hoarseness resulting from postintubation arytenoid cartilage subluxation in an 11-year-old girl. Otolaryngol Pol 1998;52:223-6.

4. Lundy DS, Casiano RR, Shatz D, Reisberg M, Xue JW. Laryngeal injuries after long-term intubation. J Voice 1998;12:360-5.

5. Santos PM, Afrassiabi A, Weymuller EA Jr. Risk factors associated with prolonged intubation and laryngeal injury. Otolaryngol Head Neck Surg 1994;111:453-9.

6. Panda NK, Mann SB, Raja BA, Batra YK, Jindal SK. Fibreoptic assessment of post intubation laryngotracheal injuries. Indian $\mathrm{J}$ Chest Dis Allied Sci 1998;38:241-7.

7. Benjamin B. Prolonged intubation injuries of the larynx: Endoscopic diagnosis, classification and treatment. Annal Otol Rhinol Laryngol Suppl 1993;160:1-15.

8. Colice GL. Resolution of laryngeal injury following translaryngeal intubation. Am Rev Respir Dis 1992;145:361-4.
9. Rajagopalan R, Rajaram R, Pai M, Mahendran S, Praveen RJ, Baskaran A. Incidence and risk factors of post-extubation stridor in a cohort of adult intensive care patients in South India (abstract). Indian J Crit Care Med 1999;3:75-6.

10. Kastanos N, Estopa Micro R, Marin Perez A, Xaubet Mir A, Augusti-Vidal A. Laryngotracheal injury due to endotracheal intubation: Incidence, evolution and predisposing factors: A prospective long-term study. Crit Care Med 1983;11:362-7.

11. Hsu CL, Chen KY, Chang CH, Jerng JS, Yu CJ, Yang PC. Timing of tracheostomy as a determinant of weaning success in critically ill patients: A retrospective study Crit Care 2005;9:R46-52.

12. Ellis SF, Pollak AC, Hanson DG, Jiang JJ. Videolaryngoscopic evaluation of laryngeal intubation injury: Incidence and predictive factors. Otolaryngol Head Neck Surg 1996;114:729-31.

13. Volpi D, Lin PT, Kuriloff DB, Kimmelman CP. Risk factors for intubation injury of the larynx. Annal Otol Rhinol Laryngol 1987;96:684-6.

14. Granja C, Faraldo S, Laguna P, Gois L. Control of the endotracheal cuff balloon pressure as a method of preventing laryngotracheal lesions in critically ill intubated patients. Rev Esp Anestesiol Reanim 2002;49:137-40.

Source of Support: Nil, Conflict of Interest: None declared. 